\section{Case Reports in Neurology}

Case Rep Neurol 2020;12:91-96

DOI: 10.1159/000501902

Published online: December 14, 2020
(C) 2020 The Author(s) www.karger.com/crn

This article is licensed under the Creative Commons Attribution-NonCommercial 4.0 International License (CC BY-NC) (http://www.karger.com/Services/OpenAccessLicense). Usage and distribution for commercial purposes requires written permission.

\title{
A Case of Occlusive Radiation Vasculopathy Presenting as Bilateral Internal Carotid Artery, Left Middle Cerebral Artery Occlusion and Literature Review
}

\author{
Yung-Chuan Huang ${ }^{a}$ Shin-Leh Huang ${ }^{a, b}$ Hon-Man Liu ${ }^{c, d}$ \\ Hou-Chang Chiu ${ }^{\text {a, }}$ \\ aDepartment of Neurology, Fu Jen Catholic University Hospital, Fu Jen Catholic University, \\ New Taipei City, Taiwan; ${ }^{b}$ Department of Biomedical Engineering, National Yang-Ming \\ University, Taipei, Taiwan; ${ }^{~}$ College of Medicine, Fu Jen Catholic University, New Taipei \\ City, Taiwan; ${ }^{d}$ Department of Radiology and Medical Imaging, Fu Jen Catholic University \\ Hospital, Fu Jen Catholic University, New Taipei City, Taiwan
}

\section{Keywords}

Radiation vasculopathy · Carotid stenosis - Radiotherapy · Head and neck cancer - Ischemic stroke

\begin{abstract}
Radiation vasculopathy is one of the rare causes of ischemic stroke. Carotid stenosis with large volume infarction may occur years after radiation therapy for head or neck cancer. We report a case of a patient with bilateral internal carotid artery occlusion presenting with left middle cerebral artery infarct 10 years after receiving treatment for tongue cancer. A literature review and discussion of treatment for such patients are presented.




\section{Case Reports in Neurology}

\section{Introduction}

Radiation therapy is a kind of cancer treatment that is widely applied for eradiating cancer cells or controlling tumor growth of primary radiation-sensitive cancer or metastatic head and neck cancer. Although precise medicine with localized irradiation is currently the standard treatment, damage to the normal tissue cannot be completely avoided. The complications of radiation therapy are typically divided into acute effects that can occur during irradiation or up to several weeks later, early-delayed effects that appear up to 6 months after irradiation, and late effects that occur at $\geq 6$ months after irradiation.

Radiation-induced vasculopathy is a well-recognized late complication that was reported as early as 1960s [1]. Focal small-vessel arteriopathy, moyamoya arteriopathy, and microbleeds have been noted in survivors of brain tumors who received radiation therapy several years previously $[2,3]$. The risk factors of developing radiation vasculopathy include patient receiving adjunctive chemotherapy, receiving radiotherapy at a young age, a higher radiation dose, or having other vascular risk factors.

Carotid stenosis is a more frequent complication in patients who received radiation therapy for neck and head tumors [4, 5]. Because the incidence of cancer has increased in recent years, occlusive radiation vasculopathy has become an increasingly prevalent risk factor for transient ischemic attack and ischemic stroke.

\section{Case Report}

A 63-year-old man suffered from sudden onset of right hemiparesis, hemianopsia, and aphasia while eating breakfast with his family at home. The patient had a history of tongue cancer that was treated by surgical excision and radiation therapy 10 years ago without recurrence or complications. He was receiving regular medication for controlling hypertension and was a smoker. He was immediately transported by ambulance to the emergency room. Brain computed tomography (CT) performed revealed no intracranial hemorrhage, and his score on the National Institutes of Health Stroke Scale (NIHSS) was 17. Thrombolysis therapy (recombinant tissue plasminogen activator $0.9 \mathrm{mg} / \mathrm{kg}$ ) was administered approximately $1 \mathrm{~h}$ after the onset of symptoms. The patient gradually recovered over the following $2 \mathrm{~h}$ (NIHSS 17 to 3), with sequelae of mild dysarthria, right central palsy, and right upper limb clumsiness.

Owing to the suspicion of large-vessel occlusion, for which endovascular therapy might be indicated, cerebral CT angiography (Fig. 1) was performed, which revealed the obliteration of the bilateral proximal internal carotid arteries (ICAs) from the cervical to the petrous segments, with reconstitution of the anterior cerebral circulation by the bilateral external carotid arteries. A perfusion study performed showed remarkably prolonged time to peak, delay of mean transmit time, and decrease of cerebral blood flow but normal cerebral blood volume at the left middle cerebral artery (MCA) and anterior cerebral artery regions. Emergency angiography and mechanical thrombectomy were attempted; however, these approaches revealed tandem stenosis of the left ICA and MCA that was difficult to manage using any available device.

The patient was admitted to the intensive care unit with an NIHSS of 3, where persistent extremely high blood pressure (systolic blood pressure [SBP] $>220 \mathrm{~mm} \mathrm{Hg}$ ) was recorded. A perdipine pump was applied $7 \mathrm{~h}$ after thrombolysis therapy after two injections of labetalol failed to control his blood pressure. His blood pressure rapidly decreased (SBP $<100 \mathrm{~mm} \mathrm{Hg}$ ),

\section{Karger'=}




\section{Case Reports in Neurology}

Case Rep Neurol 2020;12:91-96 DOI: $10.1159 / 000501902$

(c) 2020 The Author(s). Published by S. Karger AG, Basel www.karger.com/crn

Huang et al.: A Case of Occlusive Radiation Vasculopathy Presenting as Bilateral Internal Carotid Artery, Left Middle Cerebral Artery Occlusion and Literature Review

although the perdipine pump was immediately discontinued, and a large volume of normal saline was infused. Stroke in evolution with global aphasia and right hemiplegia immediately developed. Magnetic resonance imaging (Fig. 2) confirmed a thrombotic infarct in the left MCA territory and occlusion of the bilateral ICAs. Although dual antiplatelet therapy with aspirin and clopidogrel was prescribed, neurologic deficits remained following the acute stage. His daily activity was almost totally dependent (modified Rankin scale: 4) even after 1 month of intensive ambulation training at the hospital.

\section{Discussion}

We report a case of occlusive radiation vasculopathy, which is a severe late complication of radiation therapy with unclear underlying pathophysiology. Tissue necrosis and inflammation are considered as the main causes of radiation vasculopathy $[3,6]$. Endothelial cell damage directly caused by radiation cytotoxicity results in small-vessel necrosis. Hypoxia induces damages and demyelinating changes to other vessels over the corresponding areas. The blood-brain barrier is disrupted, and diffuse atherosclerosis, hyalinization, and even microbleeds may occur months to years after brain irradiation. Although the chief culprit in chronic occlusive radiation vasculopathy remains an issue, the most radiosensitive mesenchymal cells that are common to the artery proper and vasa vasorum appear as the victims of radiation therapy [7]. The occurrence of extensive endothelial damage is followed by accelerated chronic inflammation and atherosclerosis.

Occlusive radiation vasculopathy has primarily been diagnosed from a history of irradiation years before onset and corresponding image findings on angiography, CT angiography, or magnetic resonance angiography. Typical image findings, as observed in our patient, are tandem, diffuse steno-occlusions involving the common carotid arteries and ICAs [8]. These occlusions might be due to the chronic progressive stenosis of the bilateral carotid systems. Extensive collateral circulation is frequently observed at the first stroke presentation. As observed in our patient, deep branch or watershed infarcts are common findings. Other conditions that might contribute to vasculopathy, such as vasculitis, collagen vascular diseases, diabetes mellitus, hypertension, neurofibromatosis, primary moyamoya syndrome, and compression by tumors, have to be ruled out.

Although there have been no trials evaluating tissue plasminogen activator treatment in cancer patients with stroke or radiation vasculopathy, these are not exclusive conditions in most guidelines if the patient has acceptable life expectancy and abilities in activities of daily living. Cohort and small case series studies have suggested that the similar rates of symptomatic bleeding and improvement in neurological condition are encountered in patients with cancer treated with intravenous thrombolysis $[9,10]$.

Endovascular therapy is another recanalization therapy for large vessel disease in acute ischemic stroke. Although there have been no clinical trials in patients with cancer, case series have suggested that endovascular therapy is beneficial for selected patients with good premorbid functional status [11]. Among 32,576 patients with stroke treated with intravenous thrombolysis, some of whom also received endovascular therapy, and 807 patients with comorbid cancer, the overall rate of intracerebral hemorrhage was similar in patients with $(6.3 \%)$ and without $(6.4 \%)$ cancer [12]. The rate of in-hospital mortality did not differ between the two groups.

\section{Karger'=}




\section{Case Reports in Neurology}

Case Rep Neurol 2020;12:91-96 DOI: 10.1159/000501902

(c) 2020 The Author(s). Published by S. Karger AG, Basel www.karger.com/crn

Huang et al.: A Case of Occlusive Radiation Vasculopathy Presenting as Bilateral Interna Carotid Artery, Left Middle Cerebral Artery Occlusion and Literature Review

However, fewer patients with cancer have received thrombolytic therapy in the acute stage of ischemic stroke. Because of concern regarding the bleeding risk in radiation-induced vasculopathy, we followed the blood pressure control protocol of thrombolytic therapy (SBP $<185 \mathrm{~mm} \mathrm{Hg}$ ) in our patient. However, due to long-term large-vessel disease with poor autoregulation ability, excessive blood pressure control might induce the disruption of cerebral perfusion. Enlargement of the ischemic core occurred in our patient when his blood pressure decreased. More careful and intensive blood pressure control is indicated.

We emphasize the importance of following up for carotid stenosis following radiation therapy. With progress in surgical technique, radiation therapy, and adjuvant treatment, the survival rate of patients with head and neck cancer has considerably improved in recent years. Although there are no regular screening data for patients after radiation therapy, the incidence of carotid stenosis following radiation therapy appears to be underestimated. In a previous cross-sectional study, carotid artery stenosis (defined as $>70 \%$ occlusion) was observed in approximately $12 \%$ of patients at about 6 years after irradiation [5]. Because the percentage of patients having stenosis prior to the initiation of therapy is unclear, the contribution of radiation injury to the risk of carotid artery stenosis is difficult to evaluate. However, similar results were observed in a case series that reported that the risk of critical stenosis in the carotid system was elevated at approximately 5 years after irradiation [4]. In patients aged $<60$ years, the 15-year cumulative risk of stroke following irradiation of the neck was $12.0 \%$ [13].

Radiation vasculopathy is mainly caused by diffuse atherosclerosis following endothelial injury from radiation. The intensive control of vascular risk factors and use of antiplatelet agents would be the best strategy unless the patient had arrhythmia or cancer-mediated hypercoagulability. Owing to the high prevalence of critical stenosis of the carotid system, aggressive therapy, such as carotid stenting or endarterectomy, should be considered early. The high risk of restenosis (up to $20-60 \%$ within 2 years) must be taken into account $[14,15]$.

\section{Conclusions}

Occlusive radiation vasculopathy is a severe late complication of radiation therapy. The intensive control of vascular risk factors and regular evaluation of carotid stenosis are indicated for patients with this complication, particularly for those who underwent therapy at a younger age, received a higher dose of radiation, or were coadministered chemotherapy. Aggressive thrombolytic therapy is appropriate during the acute stage. Extensive large-vessel disease with poor autoregulation ability may be encountered in these patients. Close monitoring of neurological condition as well as careful blood pressure control must be provided. Carotid stenting or carotid endarterectomy will be necessary if high-grade stenosis occurs.

\section{Acknowledgement}

We would like to thank the Department of Neuroradiology, Fu Jen Catholic University Hospital, Fu Jen Catholic University for contributing with the image scans.

\section{Karger'=}




\section{Case Reports in Neurology}

\section{Statement of Ethics}

The authors have no ethical conflicts to disclose.

\section{Conflict of Interest Statement}

The authors have no conflicts of interest to declare.

\section{Funding Sources}

The authors have no funding sources to disclose.

\section{Author Contributions}

There is equal contribution from all authors.

\section{References}

1 Darmody WR, Thomas LM, Gurdjian ES. Postirradiation vascular insufficiency syndrome. Case report. Neurology. 1967 Dec;17(12):1190-2.

2 Roongpiboonsopit D, Kuijf HJ, Charidimou A, Xiong L, Vashkevich A, Martinez-Ramirez S, et al. Evolution of cerebral microbleeds after cranial irradiation in medulloblastoma patients. Neurology. 2017 Feb;88(8):78996.

3 Murphy ES, Xie H, Merchant TE, Yu JS, Chao ST, Suh JH. Review of cranial radiotherapy-induced vasculopathy. J Neurooncol. 2015 May;122(3):421-9.

4 Cheng SW, Ting AC, Lam LK, Wei WI. Carotid stenosis after radiotherapy for nasopharyngeal carcinoma. Arch Otolaryngol Head Neck Surg. 2000 Apr;126(4):517-21.

5 Cheng SW, Wu LL, Ting AC, Lau H, Lam LK, Wei WI. Irradiation-induced extracranial carotid stenosis in patients with head and neck malignancies. Am J Surg. 1999 Oct;178(4):323-8.

6 Nordal RA, Wong CS. Molecular targets in radiation-induced blood-brain barrier disruption. Int J Radiat Oncol Biol Phys. 2005 May;62(1):279-87.

7 Fajardo LF. Is the pathology of radiation injury different in small vs large blood vessels? Cardiovasc Radiat Med. 1999 Jan-Mar;1(1):108-10.

8 Zou WX, Leung TW, Yu SC, Wong EH, Leung SF, Soo YO, et al. Angiographic features, collaterals, and infarct topography of symptomatic occlusive radiation vasculopathy: a case-referent study. Stroke. 2013 Feb;44(2):401-6.

9 Masrur S, Abdullah AR, Smith EE, Hidalgo R, El-Ghandour A, Rordorf G, et al. Risk of thrombolytic therapy for acute ischemic stroke in patients with current malignancy. J Stroke Cerebrovasc Dis. 2011 MarApr;20(2):124-30.

10 Cappellari M, Carletti M, Micheletti N, Tomelleri G, Ajena D, Moretto G, et al. Intravenous alteplase for acute ischemic stroke in patients with current malignant neoplasm. J Neurol Sci. 2013 Feb;325(1-2):100-2.

11 Merkler AE, Marcus JR, Gupta A, Kishore SA, Leifer D, Patsalides A, et al. Endovascular therapy for acute stroke in patients with cancer. Neurohospitalist. 2014 Jul;4(3):133-5.

12 Murthy SB, Karanth S, Shah S, Shastri A, Rao CP, Bershad EM, et al. Thrombolysis for acute ischemic stroke in patients with cancer: a population study. Stroke. 2013 Dec;44(12):3573-6.

13 Dorresteijn LD, Kappelle AC, Boogerd W, Klokman WJ, Balm AJ, Keus RB, et al. Increased risk of ischemic stroke after radiotherapy on the neck in patients younger than 60 years. J Clin Oncol. 2002 Jan;20(1):282-8

14 Protack CD, Bakken AM, Saad WE, Illig KA, Waldman DL, Davies MG. Radiation arteritis: a contraindication to carotid stenting? J Vasc Surg. 2007 Jan;45(1):110-7.

15 Shin SH, Stout CL, Richardson AI, DeMasi RJ, Shah RM, Panneton JM. Carotid angioplasty and stenting in anatomically high-risk patients: safe and durable except for radiation-induced stenosis. J Vasc Surg. 2009 Oct;50(4):762-7. 


\section{Case Reports in Neurology}

\begin{tabular}{l|l}
\hline Case Rep Neurol 2020;12:91-96 \\
\hline DOI: 10.1159/000501902 & $\begin{array}{l}\text { @ 2020 The Author(s). Published by S. Karger AG, Basel } \\
\text { www.karger.com/crn }\end{array}$ \\
\hline
\end{tabular}

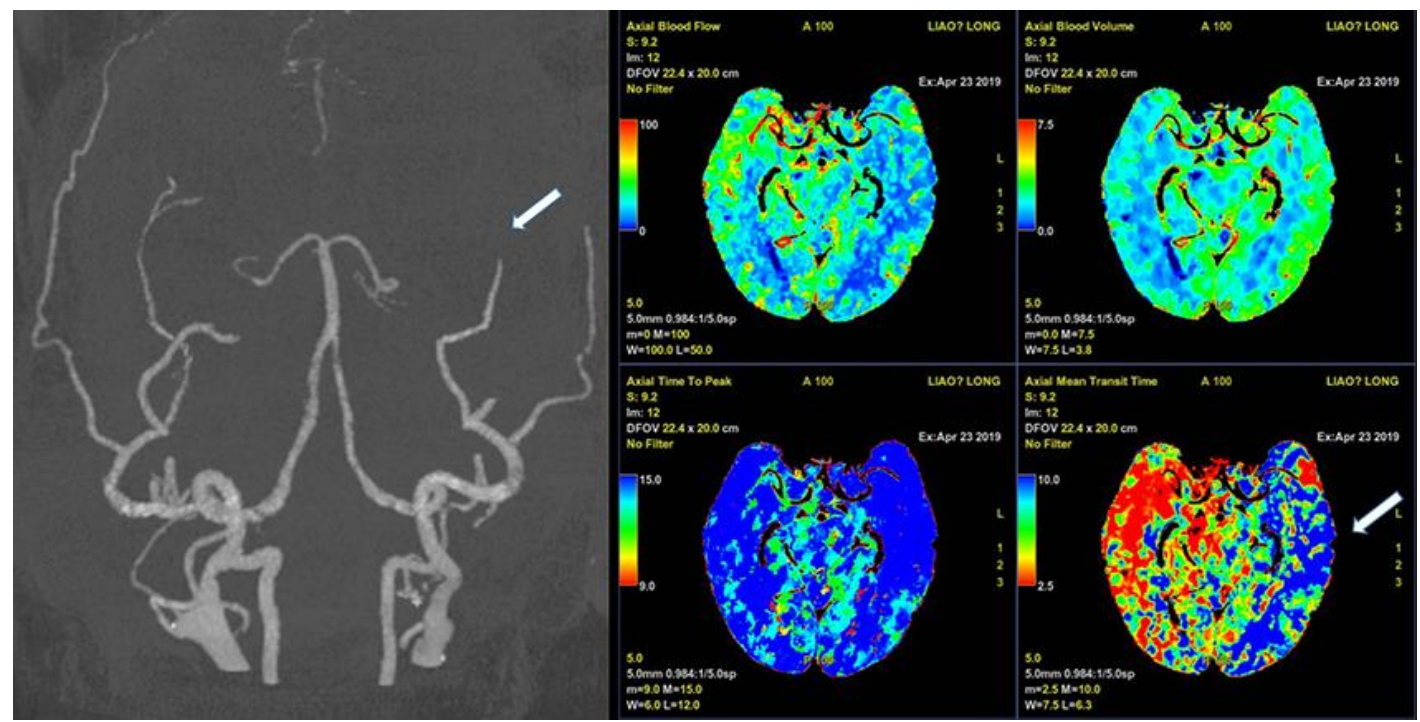

Fig. 1. Post-contrast cerebral computed tomography angiography and perfusion scan reveal the obliteration of the bilateral proximal internal carotid arteries from the cervical to the petrous segments, with the reconstitution of the anterior cerebral circulation by the bilateral external carotid arteries. Perfusion study shows mismatch in the left middle cerebral artery territory.

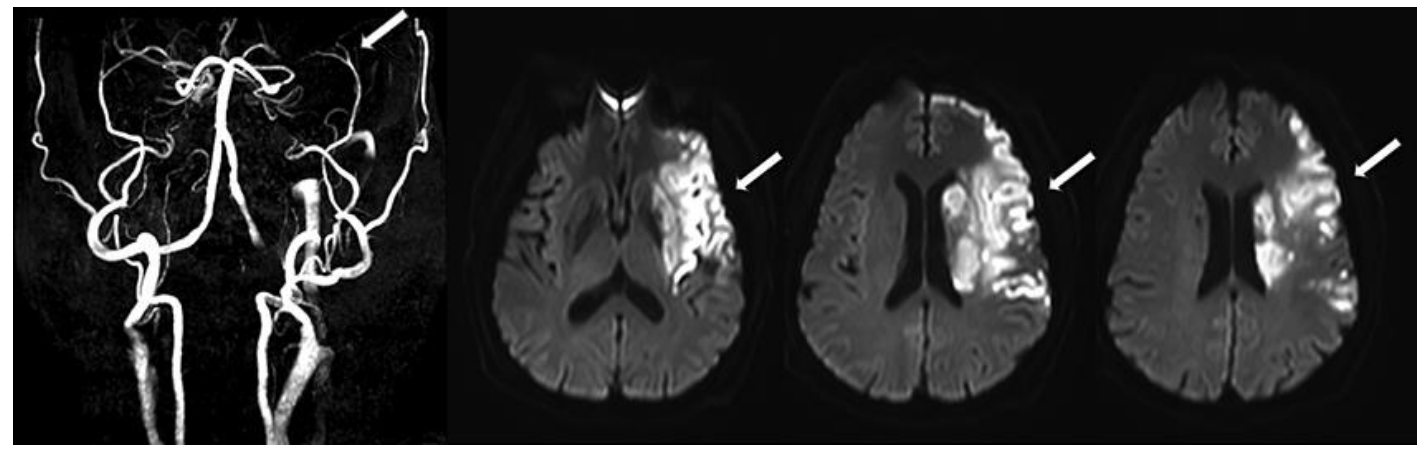

Fig. 2. Magnetic resonance imaging of the brain without contrast shows a bright lesion in the left middle cerebral artery territory on diffusion-weighted imaging, indicating an acute ischemic infarct. Magnetic resonance angiography shows total occlusion of the bilateral internal carotid arteries from the cervical to the intracranial portions.

\section{Karger'}

